\title{
Introducing the Nordes special issue on Experiments in Design Research: Expressions, Knowledge, Critique
}

\author{
Thomas Markussen ${ }^{1}$ \& Anna Vallgårda ${ }^{2}$, \\ ${ }^{1}$ Design School Kolding, ${ }^{2}$ IT University of Copenhagen
}

Design is closely affiliated with the experimental, which is an exploratory and probing undertaking. What does this mean in the context of design research? Today, design research relies on various and divergent notions of design experimentation and ideas about their value and uses. Within one strand of work, experimentation is conceived of as designerly exploration into, for instance, materials, technologies, and expressions. In another, experiments may take the form of experimental research where methods and theories are interpreted and reinterpreted in a design context and sometimes brought together in unexpected bricolages. In a third line of work, design experimentation is shaped according to hypothetical-deductive models of knowledge production inherited from science and engineering. Yet, within a fourth strand of work, design experiments are explored as a means for promoting social change or as a critique of political and ethical values. For instance, this can take the form of critique through fiction and utopias.

This raises a set of central questions for design research: How is design experimentation similar and different from experimentation in other research fields and areas? What is the role of exploration visà-vis experimentation in design research? How is it possible to provide a consistent account of research methods underlying experimental design research? Is it possible to stage design experiments other than as highly idealized probing situations? How can design experiments act as part of a critical aesthetic practice?

In this special issue we have invited a selection of authors to expand their papers from the Nordes 2013 conference. We have chosen papers which together shed some light on these questions and demonstrate a width and richness in current experimental design research. To set the scene, the issue opens with Dagmar Steffen's paper on New experimentalism in design research, wherein she provides a broad and nuanced contextualisation of experimentation in science, art and design.

As proponents for the designerly experiments we have invited Welby Ings and Michael Jasper. Ing's work is representative of an artistic research practice using subjective experience and autobiographical material as drivers for artistic expression in filmmaking. Jasper uses a more traditional research approach in analysing the qualities of experimental studio practices of two prominent architects: John Hejduk and Colin Rowe.

\begin{abstract}
Anne Louise Bang \& Mette Agger Eriksen use autobiographical material from their doctoral dissertations as means to develop a formal framework for understanding how design experiments drift and transform throughout a research process. They introduce a group of researchers experimenting with ways of using methods and theories in design research practice. Jung-Joo Lee shows through her students' work how methods like cultural probing are not readily applicable without experimental appropriation. In this group we also find Ted Matthews who through hermeneutic experimentation merges theories of the sacred with service design.
\end{abstract}

Li Jönsson \& Tau Lenskjold play on several experimental levels when, through the surprising merger of critical design and co-design, they are able to produce a speculative environment suitable for exploring emergent research themes. Jönsson \& Lensskjold bridge both the experimental research strand and the use of fiction and utopias in design research. In the last paper, Eva Knutz, Thomas Markussen \& Poul Rind Christensen analyse the qualities of using fiction in design experiments on an architectural and urban scale.

The making and editing of this special issue would not have been possible without all the valuable comments and the immense help and copious advice that we have received from a group of anonymous 
peer reviewers to whom we would like to express our gratitude. Our hope with this issue is to have shown that the different strands of design experimentation are not tied up to specific domains but may flourish cross-disciplinary from architecture to interaction design to filmmaking.

Happy reading!

Thomas Markussen \& Anna Vallgårda 